towards data synthesis, broad regional analyses and model building. It demonstrates clearly that archaeology today is problem-orientated rather than artefactorientated. The problems now under examination by archaeologists of ten centre on the dynamics of interactions between man, his technology and the environment. Systems theory and feedback models provide valuable ways of examining such interactions, and indeed many of the sections in the Encyclopedia are structured either implicitly or explicitly around these conceptual frameworks.

A systems approach becomes a particularly useful tool in archaeology when analysing the emergence of entirely new levels of organization. No longer are such new levels viewed by archaeologists as periods of abrupt revolutionary technological or behavioural change, but instead are seen as periods of adjustment and readjustment to changing configurations of resources and knowledge. The origins of agriculture form one of the more intriguing applications of systems theory. At the end of the last glacial, environmental changes apparently provided both the opportunity and the necessity for the increasingly specialized exploitation of food resources. What is well demonstrated in the chapters on the origins of agriculture in the Near East, Africa and the Far East is that this new and unique strategy for human survival occurred, apparently independently, in several areas. Thus, in each of these major regions, and in at least one centre in the New World, human populations responded to the changing postglacial world in a recurring pattern of increased utilization of a small number of wild foods. It was this emerging dependency on wild foods which led to their ultimate control and domestication. And it was this control over local food resources that paved the way for an increasingly sedentary way of life.

The variety of subjects covered by the book is indeed encyclopaedic. While most of the chapters consist of regional analyses of important phases in human history the origin and development of agriculture, cities and empires, for example - other relevant topics such as early human evolution and dating techniques have not been neglected. The geographical scope, however, is somewhat uneven. Of a total of 64 chapters, only seven (eight if one includes Oceania) are devoted to the archaeological history of the New World. While it may be conceded that the Old World was long the central focus of human development, surely the entire Western Hemisphere merits more discussion than these few rather perfunctory chapters. Moreover, certain major problems in New World prehistory, such as the probable timing and route of human entry, have not even been mentioned.

In the final analysis, the faults of The Cambridge Encyclopedia of Archaeology are few. The short, well-illustrated

chapters are suited for both browsing and more directed reading, while their content will inform all but the specialist. Although price is a drawback, this would be an extremely useful text for broad survey courses in archaeology. The consistent emphasis on method, theory and recent

research, the bibliography and broad geographical and temporal scope all combine to make this a volume with wide appeal.

Gail Kennedy is at the Department of Anthropology, University of California, Los Angeles.

\title{
Cancer: how much of a business?
}

\section{D.G. Harnden}

The Cancer Syndrome. By Ralph W. Moss. Pp.347. (Grove Press: 1980.) \$12.95, US only.

IT IS usually assumed that those involved in cancer research are motivated by a desire to rid the world of the disease. While this may be partly true, intellectual curiosity and concern for individual patients are often the most potent driving forces. Ralph Moss, however, tells us something different. Cancer research in the USA is, he says, largely manipulated by big business in the hope of financial gain; manipulated by those who believe that a cancer cure will make a fortune for the holder of the patent and by those who fear that preventive measures will involve cleaning up a profitably polluted environment. The medical profession too, he suggests, are part of this conspiracy, favouring treatments which ensure a handsome profit.

It would be easy to dismiss Moss's book as inaccurate in detail and outrageously biased, but to do so would be to fail to acknowledge that some of the criticisms that he makes seem well aimed and that the issues he raises are of considerable importance. Unfortunately, he does not spell out or consider in any constructive way the main issue that he raises, namely "What is the proper relationship between the fundamental discoveries of biological science and the industry that can make these discoveries available to the general public?".

There are two central allegations around which the book is built. First, that orthodox treatment is unsuccessful and that the cancer establishment in the USA will take any steps to ensure that new developments which are not patentable are stifled at birth or as soon thereafter as possible. Second, that little emphasis has been placed on prevention because it would be more profitable to find a patentable cure and because prevention might involve fundamental and expensive alterations in industrial practices.

Is there any truth in either of them? For the commonest cancers it is true that the results of conventional treatment are not good. In breast cancer the five-year survival rate is approximately $50 \%$ (and, as Moss reminds us, five-year survival is not cure), while for lung it is a disasterous $5 \%$. Even worse, neither figure is improving. When we say that improvements have occurred over the past few years it is essentially in cancers that are uncommon, such as Hodgkin's disease and in the childhood neoplasms such as Wilm's tumour. But many cancer patients are cured and many more are given a greatly improved quality of life, so there is, at least, some over-statement. However, when Moss points to over-optimistic propaganda about cures it is hard to disagree with him - we have a long way to go. He therefore suggests that we turn to unorthodox methods such as laetrile, Coley's toxin, hydrazine sulphate and vitamin $C$, and says that information that such methods are already successful has been deliberately suppressed. In a vitriolic attack on the Memorial Sloane Kettering Cancer Centre, the American Cancer Society and the National Institutes of Health, he accuses these institutions and specific individuals of blocking grant awards for research in these areas and of granting awards to others for their help in this process.

As a science writer sacked from the Memorial Sloane Kettering for misrepresenting the work of the Institution, Moss can hardly be without bias - but he is well informed. He shows that the governing bodies of the Memorial Sloane Kettering Cancer Centre and the American Cancer Society have a large representation of those whose business connections could lead to a conflict of interest. Obviously there are altruistic reasons why industrialists and financiers would wish to serve on the board of a cancer centre, but there could be less worthy reasons. Although overt attempts to influence scientific policy would obviously be resisted by the scientific staff, the possibility of indirect influences, especially by those who donate very large sums of money to the institutions, must be a matter for concern. Moss also points to the form of contract between the Memorial Sloane Kettering Cancer Centre and the chemical companies which seems to grant all the advantages to the companies. This is not an easy matter, and the link between industry and the scientist often poses a dilemma. Anyone in cancer research who has a connection with industry is liable to be accused of having compromised his scientific integrity. However, Moss is more concerned with undermining the present structure than with suggesting improvements and the important questions are left unasked. 
It really does seem hard to believe that successful unorthodox treatments are suppressed because they are not patentable. If they were good then they would have been adopted in countries other than the USA where the allegations of corruption levelled by Moss do not apply. Moreover, Moss mentions, but gives scant attention to the need to protect the public from unscrupulous frauds. There are too many documented cases to ignore the fact that National Institutes of Health, the American Cancer Society and similar bodies have a duty not only to promote research, but also to protect the public from quacks. So the first charge is not entirely proven; nonetheless, Moss's book leaves an uncomfortable feeling that all is not well.

When he turns to cancer prevention (or the lack of it) he is on firmer ground. There is plenty of evidence that in the past, and also at present, some parts of industry have callously ignored the welfare of their workers. Moss revels in the horrors of asbestos and mesothelioma. These facts have been well documented elsewhere, however, and are no longer the main issue. $\mathrm{He}$ is quite wrong in saying that research into preventive methods has been ignored; this only reveals his limited horizons. There is at present a great deal of activity in basic research laboratories and in industrial laboratories to find ways of preventing the widespread use of hazardous chemicals. Again, this needs collaboration between industry and basic research, but the relationship is not always an easy one. Any scientist who helps a company to sort out a problem is likely to be branded a consultant - and therefore suspect - by people such as Moss. This should not be so - the expertise in the universities and research institutes should be available to industry. On the other hand, it does cause concern that one distinguished scientist and government adviser should also be found to be a consultant for six large corporations and two manufacturers' associations.

The book is well written and easy to read. In an era in which monoclonal antibodies and the production of specific polypeptides by genetic manipulation are likely to become big business, it raises issues that have to be faced. The manner in which the issues are raised, however, leaves a rather nasty taste in the mouth.

D. G. Harnden is Professor of Cancer Studies at the University of Birmingham, UK.

\section{State of the art in nutrition}

\section{J.W.T. Dickerson}

\begin{abstract}
Human Nutrition-A Comprehensive Treatise. General editors R. B. Alfin-Slater and D. Kritchevsky. (Plenum: 1979/1980). Vol. 1. Nutrition: Pre- and Postnatal Development (edited by M. Winick), pp.495; £24.89, \$39.50. Vol. 2. Nutrition and Growth (edited by D.B. Jelliffe and E.F.P. Jelliffe), pp.450; £23.63, \$37.50. Vol. 3A. Nutrition and the Adult: Macronutrients, pp.290; $£ 15.75, \$ 25$. Vol. 3B. Nutrition and the Adult: Micronutrients, pp.424; $£ 24.89, \$ 39.50$. (Both edited by R.B. Alfin-Slater and D. Kritchevsky.) Vol. 4. Nutrition: Metabolic and Clinical Applications (edited by R.E. Hodges), pp.478; £23.63, \$37.50.
\end{abstract}

THIs large work has grown out of an idea "to provide the research investigator and the advanced graduate student with an upto-date report on the state of the art". Originally intended as one volume, the treatise now has four volumes and one (Vol.3) has two parts.

Volume 1 deals with the role of nutrition in pre- and postnatal development, and starts with a discussion of nutrition and the metabolic development of mammals. Metabolic status at various stages of development is closely related to the quality and quantity of the nutrients consumed. The author (Hahn) suggests that the old idea that nutrients act directly on most cells must be discarded and replaced by a concept that, mostly, nutrients have immediate and long-term effects by acting on selected endocrine cells, which then release their hormone to act on target cells. It is this combined effect which controls the development of enzyme systems, cells and tissues.

The development of the brain is important in controlling the ability of the organism to respond to its environment and malnutrition may, because of the timescale over which the brain develops, have permanent deleterious effects upon it. The importance of this subject is reflected in several of the following chapters.

Nutrition and pregnancy is largely discussed from the viewpoint of the effects of disturbances in maternal nutrition on the growth and development of the foetus. The effects of nutrient excesses and of interactions of drugs with nutrients are briefly mentioned. This leads logically to a discussion of breast feeding by Jelliffe and Jelliffe who make the point that the matters that need emphasis are the same the world over.

The contribution on the interactions of nutrition and infection includes a discussion of the problem of the septic patient. In the chapter on the relationship of nutrition to dental development and disease the need is emphasized for more studies to explore the mechanisms and consequences of nutrient deficiencies to oral health. The recognition that atherosclerosis may be a paediatric problem is dealt with. Although this is a prudent approach it is emphasized that proof is at present lacking. A brief chapter is devoted to inborn errors - principles and not details. The final chapter discusses the management of chronic diarrhoea in children.

The second volume, concerned with nutrition and growth, draws attention to the diffuse nature of the subject, the value of having different perspectives, and the fact that there are few "absolute" answers to the various problems such as standards for growth and dietary allowances.

The first chapter considers the problem of nutrient needs. In the absence of proper experiment, the tendency is to consider present intake as "ideal requirements". In the next chapter the complex interrelationships between genetic constitution and nutrition are discussed. The influence of non-dietary factors is dealt with, as also is the problem of metabolic anomalies.

Part II is concerned with the ages of man and is introduced by a chapter on maternofoetal nutrition which presents results of the 1969 longitudinal INCAP study. This leads logically to a consideration of the nutrition of the fullterm and premature baby. The need for further work on the problems of the latter is emphasized. Four chapters are then devoted to the young child and discuss the normal and failure-to-thrive child, proteinenergy malnutrition and obesity respectively. The adolescent, rapidly changing organism and the adult, stabilized situation between development and senescence are then discussed. Part III contains nine contributions which deal with aspects of growth monitoring and nutritional assessment and surveillance, and contains much practical information on different methods and useful tables of reference data.

Volume 3A starts with a discussion of nutrient requirements - what they are and the bases of recommendation - leading on to contributions concerned with energy requirements, the suppliers of energy and their interrelationships, the problem of energy exchange and the partition of food energy. The remaining four chapters deal with nutrients with special functions proteins and amino acids, essential fatty acids, cholesterol and dietary fibre.

Volume 3B is introduced with a chapter on vitamins, mainly those of the B-group, as co-enzymes. There are five chapters on individual vitamins and one on ironhaemoglobin. The chapter entitled "Trace Elements" starts with a somewhat scant treatment of calcium, phosphorus and magnesium. There are useful discussions of drug-nutrient interrelationships and the effects of oral contraceptives on nutrient requirements. The final chapter on nutrition of the elderly has very much a North American bias.

Volume 4 is concerned with the metabolic and clinical application of nutrition. 